\title{
The Use of Microwave Drying Process to the Granular Materials
}

\author{
Francisc Ioan Hathazi ${ }^{1}$, Vasile Darie Șoproni ${ }^{2}$, Mircea Nicolae Arion ${ }^{3}$, Carmen Otilia Molnar ${ }^{4}$ \\ Department of Electrical Engineering, University of Oradea, Oradea, Romania
}

\author{
Simina Vicaș (Coman) $)^{5}$ \\ Department of Computers and Information Technology \\ University of Oradea, Oradea, Romania
}

\author{
Olimpia Smaranda Mintas ${ }^{6}$ \\ Department of Animal Science and Agritourism \\ University of Oradea, Oradea, Romania
}

\begin{abstract}
The use of electro thermal technologies based on microwave energy represents an important step in the development of new innovative solutions. The numerical modelling allows to study the influence of the high frequency electromagnetic and thermal field on the dielectric materials during the drying process before achieving practical installation. So, when is developed the experimental model will be already known some of the phenomena that characterize the system, being eliminated a number of unknown issues. This paper describes experiments conducted to gather data on production parameters in order to improve the stored corn seed quality. The interpretation and dissemination of results triggers the description of "recipes" for drying corn seeds. The described method is flexible and can be applied to near any agricultural seeds in further researches.
\end{abstract}

Keywords-Microwave energy; microwave field; experimental models; laboratory models; drying and seed treatment

\section{INTRODUCTION}

The corn seeds storing represents an important question because the harvest is performed in different weather condition and their humidity is different from crop to crop. In order to preserve their quality, it is important to reduce their humidity to requested storage value through drying. There are various technologies used for the granular materials drying, such as: conventional drying, high frequency drying, vacuum drying, infrared drying, and various combinations of these technologies [1]. At present, the most complex microwave and radio frequency wave patterns that produce the inverse temperature gradient so if there is water inside the material, there is a moisture gradient, with its magnitude:

$\mathrm{d}=\frac{2 \cdot\left(\mathrm{u}_{\mathrm{i}}-\mathrm{u}_{\mathrm{he}}\right)}{\mathrm{s}}$

where $u_{i}$ is the moisture content inside the material, $u_{h e}$ is the moisture content corresponding to the surrounding environment in accordance with the hygroscopic balance and s is the thickness of the material.

The conventional drying rate depends on the temperature, the relative humidity and the speed of air circulation. The problem is complicated by the condensation phenomenon. In the first phase of conventional drying, free water, which exists in the cell cavities, is removed and finally the saturation point of the fibres is reached. When the humidity is $25-30 \%$ (depending on the type of material), the saturation point is reached. Therefore, the cavities contain no water, but the fibres are saturated with water. When the moisture value has been reached at equilibrium, the second drying phase moves from the surface to the inside. The drying rate at this phase is a linear function of the square root of time that indicates the drying rate controlled by the heat transfer through the material.

The distinctive features of microwave drying consist in the fact that is created a movement of moisture produced by pressure, where water will be removed by hot air [2]. Internal evaporation can generate significant pressure depending on the strength of the solid material when transporting water or vapours. This current is a different diffusion mechanism; it does not depend on the humidity concentration, and therefore cannot be described by the diffusion equation. The resulting pressure stream becomes a mechanism for transporting internal moisture and heat [3], resulting the drying.

Microwave energy affects the entire volume of the material, and due to the large differences in the dielectric loss tangent, it is absorbed mostly by the water. Because $\varepsilon^{\prime}$ and $\varepsilon^{\prime \prime}$ decrease with temperature, the heating process is stable. Absorption decreases as the temperature rises and the penetration depth increases [4], so the water is removed from the layers of the seed core.

It is clear from the literature that hybrid drying is the most flexible and economical, although some research suggests that it is more convenient to use conventional drying, while others propose the application of the hybrid technology drying, which use microwaves and air stream [3]. There are also applications where the vacuum system has a real success [5]. An important study is about determining the maximum energy that should be applied to seeds to effectively remove free water without affecting the integrity of the grain. The research carried out has concerned on different drying and treatment methods of granular agricultural products by using microwave technology for different material samples. Starting from the results obtained in previous researches [6], the solution presented in the paper proposes to analyze the possibility of drying processes using microwave systems with continuous feeding of granular material. Therefore, the microwave drying process proposed in the paper represents an important issue 
for future researches in the field, due to its advantages of improving the drying process efficiency and the quality of the seeds.

\section{MATERIALS AND METHODS}

Accordingly to von Hippel [7], the dielectric properties of a material are defined by:

$\varepsilon^{*}=\left(\varepsilon^{\prime}-j \varepsilon^{\prime \prime}\right) \varepsilon_{0}$

where: $\varepsilon^{*}$ - complex permittivity; $\varepsilon^{\prime}$ - dielectric constant; $\varepsilon^{\prime \prime}$ - dielectric loss factor; $\varepsilon_{0}$ - permittivity of free space; $\mathrm{j}$ complex operator.

The dielectric properties are dependent upon the moisture content, temperature of the material and on the frequency of the field. The larger the loss factor, the more easily the material absorbs the incident microwave energy [2]. Both the dielectric constant and the loss factor increase with moisture content, but decrease with frequency. The dielectric properties of corn over a wide range of moisture contents (11.1 to 53.9\%, dry basis) at $2.45 \mathrm{GHz}$ have been determined by Nelson [4]. The dielectric properties of a material also affect the power attenuation of the electromagnetic waves as they penetrate the loss material. Penetration depth is defined as the distance from the surface of the material at which the power drops to $1 / \mathrm{e}$ $(36.8 \%)$ from its value at the surface and is expressed by:

$\mathrm{p}_{\mathrm{d}}=\frac{\lambda_{0} \sqrt{\varepsilon^{\prime}}}{2 \pi \varepsilon^{\prime \prime}}$

where, $\mathrm{p}_{\mathrm{d}}$ - penetration depth; $\lambda_{0^{-}}$free space wavelength; $\varepsilon$ - dielectric constant; $\varepsilon "$ - dielectric loss factor.

The penetration depth increases with longer wavelength or, in other words, decreases with increasing frequency. The effect of temperature on the penetration depth of different foods has been studied [8]. They reported higher penetration depths at lower temperatures and frequencies, but this effect was less important at temperatures above $0^{\circ} \mathrm{C}$, than for frozen conditions [9]. Uniform distribution of the thermal field in the volume of material and precise control of power consumption are essential conditions to be met to process food. The microwave applicators are designed so that to meet these objectives, microwave technology [10], being increasingly used in the food industry.

In the case of corn seeds, the irregular changing of the dielectric loss factor with temperature and moisture content makes the prediction of the penetration depth during the drying process a tedious task. In a seed bed with high moisture, water migrates from the region with high temperatures to areas with lower temperatures, leading to condensation in cold spots [8].

The proposed presented solution with in the paper (Fig. 1) implies the analysis of the complex problem of drying the corn using the hybrid method. This presume the exposure of corn seeds to microwave radiation in order to reduce the moisture content to the desired value through heating. In order to avoid the appearance of condensation to the surface of the seeds, which would lead to the uncontrolled increase of the temperature at surface, the installation is provided with an exhauster that ensures the evacuation of the water excess from the surface through the air stream. The temperature of the exposed seeds to high frequency electromagnetic field is monitored in real time by means of the temperature sensors, thus being controlled the time exposure to microwave of the processed corn seeds. The microwave energy supplied by the microwave generator is transferred to the grains upon heating thereof by means of the special design of the radiating antennas [11]. The microwave system was designed so as to allow the continuous processing of the granular products, their displacement in the microwave field being realized through a helical screw with blades which ensure also the homogenization of the thermal field. As follow the main constructive elements and their role in the microwave drying solution studied in the paper are presented.

The drive motor with it adjustable rotation speed, is coupled to the helical screw carrying the seeds in the microwave field. It is being used a frequency phase converter for infinitely variable speed with a constant mechanical drive motor torque.

The grain supply system allows both the continuous granular material supply subjected to microwave drying and prevents the microwaves leakage to outside.

The technical solution adopted for preventing leakage of microwaves to the outside consists of a dosing device with four blades which rotate inside one cylinder. By rotating blades, one helical auger dispenser transfers the seeds and three block access to the outside of the microwave field. Rotating blades dispensers are provided by a gear motor speed control that provides a steady transfer of seeds inside auger conveyor screw.

To protect against leakage of microwaves in external fixation in the housing supply system was used a copper wire braid with cross-cutting dimensions of $3 \times 30 \mathrm{~mm}$, arranged for the whole fixing area.

The microwave generator is designed to emit microwave energy at a frequency of $2.45 \mathrm{GHz}$, energy which is dissipated in seeds located inside the microwave applicator with screw conveyor, accomplishing heating.

The main constructive element of the source is the radiant type microwave horn antenna, which is coupling the microwave generator (magnetron). Microwave source contains all elements for producing microwave energy and radiation, respectively microwave generator (magnetron), fan, anode voltage transformer and filament, double voltage circuit (capacitor, high-voltage diode rectifiers).

The helical screw with blade rotated by an electric motor represents the constructive solution designed to move seeds in the microwave field, so as drying is accomplished. By moving the seeds in the microwave field occurs thermal dehydration, so that after drying, they will be within imposed humidity standards. 


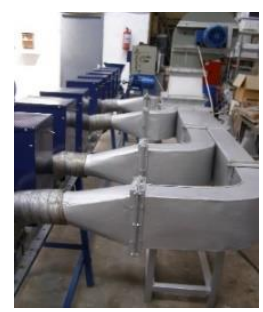

(a)

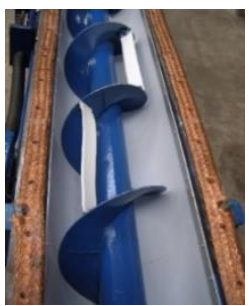

(b)

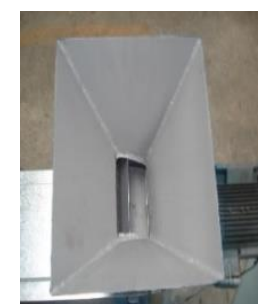

(c)
Fig. 1. The Experimental Installation. (a) Air Exhauster (b) Rotating Helical Screw Blade (c) Grain Supply System.

The exhauster has the role to evacuate humidity formed in the enclosure through the air stream produced by the blower, guiding the air flow and heat/cold air source in the microwave dryer. The air is supplied by a fan and the temperature can be raised to the desired level if so by passing it through a heating coil, the temperature control being accomplished through the thermocouple.

Prolonged exposure to microwave radiation at an intensity greater than $10 \mathrm{~W} / \mathrm{m} 2$ is a dangerous concern to the health of the users. To minimize radiation exposure to personnel working in the immediate vicinity of experimental plant, it's used perforated metal sheet through which the air jet enter in the facility. The leakage of radiation in the vicinity of equipment was constantly monitored with a leak microwave detector, in order to determine that the existing value does not exceeding safety standards.

Overall and constructive technical characteristics, the microwave drying system has the following specifications:

- Supply voltage $3 \times 380 \mathrm{~V} / 50 \mathrm{~Hz}$.

- Maximum power absorbed $15 \mathrm{~kW}$.

- Maximum power microwave generators. $7.5 \mathrm{~kW}$.

- Microwave frequency generators $2.45 \mathrm{GHz}$.

Before and after each experiment, the weight of the sample was determined with a high precision digital scale. With the measurement devices are monitored the process parameters: the microwave power input, direct power, humidity, airflow exit, adaptation of the load impedance, the temperature of the air stream, which is set so as the temperature will not exceed $55^{\circ} \mathrm{C} \pm 5 \%$ in the seed bed.

The temperature in the seed bed was determined using an optic thermometer for the seed bed. Humidity and air temperature at the output gap was determined by using the analyser Lutron YK-90HT. At the end of each experiment the stored samples of dry seeds are marked and preserved in paper bags and sent in a specialized laboratory to determine the percentage of germination.

The air supply and heat sink are turned on at least 3-5 minutes before starting the experiment to bring the system to a steady state. The temperature of the air entering the system is regulated with an accuracy of $\pm 0.5^{\circ} \mathrm{C}$ with a thermocouple. The air temperature measuring thermocouple was installed at a sufficient distance from the applicator and was protected with aluminium foil in order to avoid the induction interference that may occur in high-frequency electromagnetic field.
Thermocouples were tested for correct operation electromagnetic field by comparing the temperature read when microwave power was on and off. The readings were appropriate and validated. The relative humidity of the air at the input is not stable which causes the measurement accuracy to be in the range $5-15 \%$.

\section{NUMERICAL MODELING}

The problem was initially numerically analysed, and the results obtained being used to set the optimum operating parameters for the corn seeds microwave drying system. For the numerical simulation a professional software was used, defining a Frequency - Transient type of Study. The electromagnetic field solutions are obtained by solving Maxwell's equations, in sinusoidal state. The source field on the port is supposed known as $\mathbf{E}_{\mathrm{t}}$ (transversal electric wave) component, the internal and external sources are imposed null and on the rest of the superconducting walls the $\mathbf{E}_{\mathrm{t}}=0$. So as for the considered mathematical model, this will presume the solve of equation:

$$
\nabla \times\left(\mu_{\mathrm{r}}^{-1} \nabla \times \boldsymbol{E}\right)-\mathrm{k}^{2}\left(\varepsilon_{\mathrm{r}}-\mathrm{j} \sigma / \omega \varepsilon_{0}\right) \boldsymbol{E}=0
$$

where was considered: $\mu_{\mathrm{r}}$ - the relative magnetic permeability; $\mathrm{k}$ - the wave factor; $\varepsilon_{\mathrm{r}}$ - the relative electric permittivity; $\sigma$ is the electric conductivity $(\mathrm{S} / \mathrm{m}) ; \omega$ is the pulsation of sinusoidal quantities $\left(\mathrm{s}^{-1}\right)$.

For the considered model, the input data are the applicators work frequency $2.45 \mathrm{GHz}$, the dielectric's characteristics, the cavity excitation mode and the above boundary conditions.

An important factor for the dielectric materials processed in microwave field is represented by the thermal field and its distribution in the considered sample. During numerical computation in order to analyze the electromagnetic and thermal field is considered Frequency Transient working mode.

A complicated water diffusion problem appears, by considering the inner evaporation, where a nonhomogeneous pressure field interferes due to the water vapours [2]. Also, in the drying processes, the fast occurrence of the vapours from the inside of the dielectric sample can cause its destruction. From this consideration the maximum temperature inside the seeds needs to be limited (below $65^{\circ} \mathrm{C}$ ). From this consideration the inner evaporation can be neglected, taking into account only the one of the surface of the granular material. The surface evaporation speed depends on the difference between the surface temperature of the seeds and the ambient temperature, with respect on air pressure, to the degree of saturation of vapours, on air flow in the proximity of the charge etc.

The thermal field problem is computed for the transient regime for the heating of the supposed sample placed in the applicator. The thermal field developed in the sample is represented by the heat source associated to Joule's effect [12], [13], with its both components the heating of the material (the first term), and the heat transfer by conduction (the second term). 
$\mathrm{p}=\rho \mathrm{C}_{\mathrm{p}} \frac{\partial \mathrm{T}}{\partial \mathrm{t}}-\nabla \cdot(\lambda \cdot \nabla \mathrm{T})$

where: $\mathrm{p}$ - volume power density $(\mathrm{W} / \mathrm{m} 3), \rho$ - density $(\mathrm{kg} / \mathrm{m} 3), \mathrm{C}_{\mathrm{p}}$ - the specific heat $\left(\mathrm{J} / \mathrm{kg}^{\circ} \mathrm{C}\right), \mathrm{T}$ - temperature $\left({ }^{\circ} \mathrm{C}\right)$, $\lambda$ - thermal conductivity $\left(\mathrm{W} / \mathrm{m}^{\circ} \mathrm{C}\right)$.

The imposed boundary condition for thermal field is:

$-\lambda \frac{\partial \mathrm{T}}{\partial \mathrm{n}}=\alpha\left(\mathrm{T}-\mathrm{T}_{0}\right)$

where $\alpha$ is the thermal convection coefficient $\left(\mathrm{W} / \mathrm{m}^{2 \circ} \mathrm{C}\right)$ and $\mathrm{T}_{0}$ is the temperature on the dielectric's boundary and in the air domain $\left({ }^{\circ} \mathrm{C}\right)$.

In the boundary conditions for the thermal field problem we consider: as initial values $\mathrm{T}=\mathrm{T}_{0}\left(\mathrm{~T}_{0}=22^{\circ} \mathrm{C}\right.$ that represents the temperature of the dielectric's boundary in the air domain). Thermal Insulation: $-\mathbf{n} \cdot(-\lambda \nabla \mathrm{T})=0[11]$.

The space discretization of equation (4) in performed by using finite element method, using the same mesh as in the electric problem where the computation domain was meshed by using tetrahedral network elements. It was assigned an extra fine mesh for the dielectric material, and for the rest of the geometry was defined a coarse mesh.

The geometry of the cavity was made, having the dimensions: $240 \times 345 \times 250 \mathrm{~mm}$. The helical screw was constructed with 3 cylinders and below was placed a block representing the seed bed. The walls of the cavity and waveguide were defined as Aluminium, its interior being defined by air with its properties: electric conductivity $\sigma=0$ and $\mu_{\mathrm{r}}=\varepsilon_{\mathrm{r}}=1$. The dielectric material is corn seeds (with $26 \%$ humidity), described by $\varepsilon^{\prime}=3.5, \varepsilon^{\prime \prime}=0.66$ and $\operatorname{tg} \delta=0.19$. The thermal properties of the seeds are: $\rho=1300 \mathrm{~kg} / \mathrm{m} 3$, $\lambda=0.17 \mathrm{~W} / \mathrm{mK}$ and $\mathrm{C}_{\mathrm{p}}=1.5 \mathrm{~kJ} / \mathrm{kgK}$ [4], [14].

As input data were used different values of the power and time: microwave power of 25, 50, 75, 100, 125, 150 and 175 $\mathrm{W}$ for $300 \mathrm{~s}$; microwave power of 20, 40, 60, 80, 100, 120 of a processing time of $600 \mathrm{~s}$; and microwave power of 20,30, 40, $50,60,70 \mathrm{~W}$ for $900 \mathrm{~s}$. For each numerical simulation was noted the maximum value of the temperature measured in the whole volume of the dielectric material. The objective of the study was finding the most appropriate value of the microwave power and processing time in order to dry the mass of seeds without affecting its structure.

Fig. 2 present the maximum value of the temperature measured in the whole volume of the dielectric material for each of the above cases of microwave power. When using the processing time of $300 \mathrm{~s}$ with microwave power ranging from 25 to $175 \mathrm{~W}$ the maximum value of the temperature measured in the whole volume of the dielectric material showed values from $44^{\circ} \mathrm{C}$ (for $25 \mathrm{~W}$ ) to $135^{\circ} \mathrm{C}$ (when using $175 \mathrm{~W}$ ). Analysing the values presented in Fig. 2, the most suitable value of the microwave power when using a processing time of $300 \mathrm{~s}$ was around $75 \mathrm{~W}-100 \mathrm{~W}$.

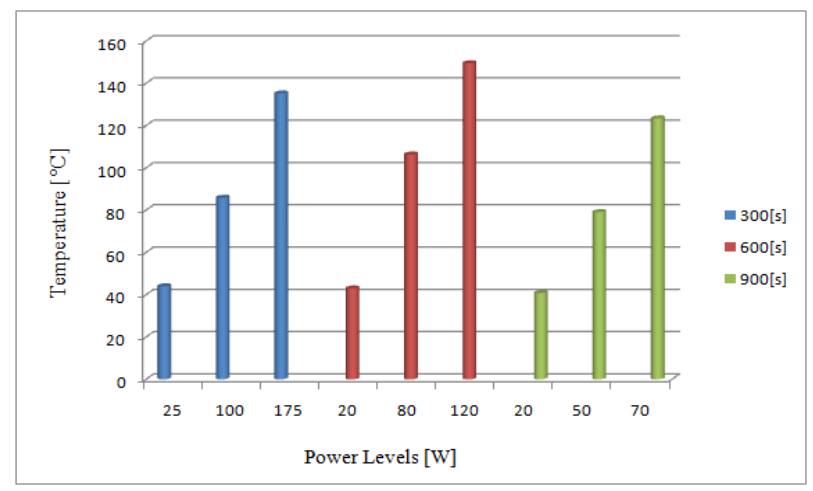

Fig. 2. The Maximum Temperatures Calculated in the Mass of the Seeds According to Microwave Power at different Values of the Processing Time.

In the case of using a processing time of $600 \mathrm{~s}$ next conclusions are being presented (Fig. 2):

- A microwave power of 20 and $40 \mathrm{~W}$ is too low for drying seeds, maximum value of the temperature measured in the whole volume of the dielectric material showed values of $42.97^{\circ} \mathrm{C}$, respectively $63.16^{\circ} \mathrm{C}$;

- A microwave power of 80,100 and $120 \mathrm{~W}$ is too high for drying seeds, maximum value of the temperature measured in the whole volume of the dielectric material showed values of $106.32^{\circ} \mathrm{C}, 127.9^{\circ} \mathrm{C}$ respectively $149.48^{\circ} \mathrm{C}$;

- The most suitable value of the microwave power considering keeping the quality of the seeds and decreasing humidity is $60 \mathrm{~W}$, the maximum value of the temperature measured in the whole volume of the dielectric material reaching $84.74^{\circ} \mathrm{C}$.

When using a processing time of 900 s the maximum value of the temperature measured in the whole volume of the dielectric material showed the best values for a microwave power of $50 \mathrm{~W}-79.1^{\circ} \mathrm{C}$. For values of the microwave power of $60 \mathrm{~W}$ and $70 \mathrm{~W}$ the temperature was $93.86^{\circ} \mathrm{C}$ and $123.41^{\circ} \mathrm{C}$ (Fig. 2).

The numerical results obtained from the simulation of the drying process, allowed to know the electromagnetic and thermal field parameters from the microwave drying equipment. Starting from the obtained values it was sought to adapt the operation parameters of the installation, thus validating the theoretical model.

\section{EXPERIMENTAL DATA}

The purpose of these experiments was to find optimal conditions based on influence of that heating in a microwave field hot / cold air has on maize seeds with high humidity. Were analysed various parameters (temperature, humidity, power) in the drying maize seeds with high humidity using a mixed process microwave / hot air. Considering the conclusions presented in the numerical simulations the effects of microwaves on drying characteristics were studied in the following cases [13]: by using a variable power microwaves with cold/hot air and by using a constant microwave power without airflow. 
Samples were performed on untreated maize corn variety Turda super (semi early variety), which is a common maize. To see and study the influence that microwaves have on seeds treated in a microwave field in the two cases above, the grains of maize were germinated and it was observed the daily evolution of the germination process.

The aim is to determine what conditions of temperature, humidity and power are favorable for germination of maize seeds treated in a microwave field. To determine the percentage of moisture removed from the seeds (STAS 10349/1-87) bed using weight of the sample before drying $\mathrm{m}_{\mathrm{i}}$ and after drying $\mathrm{m}_{\mathrm{u}}$ :

$U=\frac{m_{i}-m_{u}}{m_{u}} \times 100[\%]$

Experimental data were conducted on corn, the variety Turda Super (semi early variety) by using microwave power or mixed methods microwave power/jet of cold air. The purpose is to see what happens to the temperature and humidity seed bed where constant power use of about $1.25 \mathrm{~W} / \mathrm{g}$. Measurements were performed every 30 to 30 seconds without closing down operations and they required continuous monitoring of the power generated to not reach an excessive temperature in the seed bed. During the experiments the reflected power was kept to 0 .

1) For the first sample were used mixed methods microwave power / jet of cold air, by using a weight of 127.2 $\mathrm{kg}$ initial corn. After drying in a microwave field for 15 minutes to obtain a final weight of $114.07 \mathrm{~kg}$ of maize with a moisture proper for storage, only $13.13 \mathrm{~kg}$ standing out of water evaporated from the seed bed. Moisture removed from the seed bed is only $U=11.51 \%$. It was obtained a small amount of water released since it was used jet of cold air and thus less water was removed. At first, was applied a microwave power of $2.5 \mathrm{~W} / \mathrm{g}$ than decreasing it to $1 \mathrm{~W} / \mathrm{g}$ and furthermore, from minute 3 to a rather small power $0.50 \mathrm{~W} / \mathrm{g}$ $0.10 \mathrm{~W} / \mathrm{g}$ (see Fig. 3). Germination for this sample has a value of $75 \%$ whereas for the control sample was $92 \%$.

2) For the second sample it was used the same amount of corn seeds, as described above, but it was applied microwave power with hot air in the first 4 minutes, then cool shot was used until the end of the test period (see Fig. 4).

The initial mass was $127.2 \mathrm{~kg}$ of wet corn after drying for obtaining $112.94 \mathrm{~g}$ dried corn seeds in 15 minutes. There is a considerable difference in weight, $14.26 \mathrm{~kg}$ of water evaporated, humidity eliminated from the seed bed is $U=$ $12.62 \%$. It was obtained this small amount of moisture removed from the seed bed because there were used low levels of power: starting with $1.3 \mathrm{~W} / \mathrm{g}-1.0 \mathrm{~W} / \mathrm{g}$ decreasing to $0.1 \mathrm{~W} / \mathrm{g}$. In this case, was obtained an $80 \%$ germination rate. The first two samples stand a good plant development.
3) A new experiment was performed on the same amount of corn seeds, but only using microwave power. Note that after drying for 15 minutes, there was a difference between the initial and final weight of only $7.16 \mathrm{~kg}$ of water evaporated from the seed bed. Seeing a film of water on the surface of the seed bed, a phenomenon explained by the fact that there was used only the microwave power without airflow and thus condense occurred. Moisture removed from the seed bed is $\mathrm{U}$ $=5.96 \%$. Variation in temperature is very high in the first minute of $83.6^{\circ} \mathrm{C}-94^{\circ} \mathrm{C}$ - applied due to high power $2.0 \mathrm{~W} / \mathrm{g}$ (see Fig. 5). Note that at a power of $0.1 \mathrm{~W} / \mathrm{g}$ appears quite high humidity fluctuation in corn seed bed. Germination rate for this sample is $\mathrm{G}=25 \%$, seeds that germinated are developing normally.

4) For this samples it was used only the microwave power without air flow. Because it was used only the microwave power, without airflow to eliminate vapours from bed, was noticed a film of water on the surface of the seed bed. During the test period, the output air temperature and the temperature in the seed bed have steady growth. It was used a constant power of $0.20 \mathrm{~W} / \mathrm{g} / 15$ minutes, with an initial weight of 105.42 $\mathrm{kg}$ of wet corn and a final weight of $102.87 \mathrm{~kg}$ of dry corn. Was noticed little difference between the initial and final mass, $2.55 \mathrm{~kg}$ of water evaporated from the seeds bed, humidity eliminated from the seeds bed is $\mathrm{U}=2.47 \%$. Notice that, when using a power of $0.20 \mathrm{~W} / \mathrm{g}$ in the seed bed, the temperature increases from $21^{\circ} \mathrm{C}$ to $63^{\circ} \mathrm{C}$ value (see Fig. 6). Because these seeds have a higher moisture percentage, more energy is absorbed. Germination rate in this case is $\mathrm{G}=70 \%$, a good development of seeds. From the experimental data using only the microwave power, this sample shows the highest rate of germination. This can be explained by the fact that when using a low power, constant $0.2 \mathrm{~W} / \mathrm{g} / 15$ minutes in the seed bed the temperature did not exceed the amount of $63^{\circ} \mathrm{C}$. Germination rate of the 5 samples of corn is shown in Fig. 7.

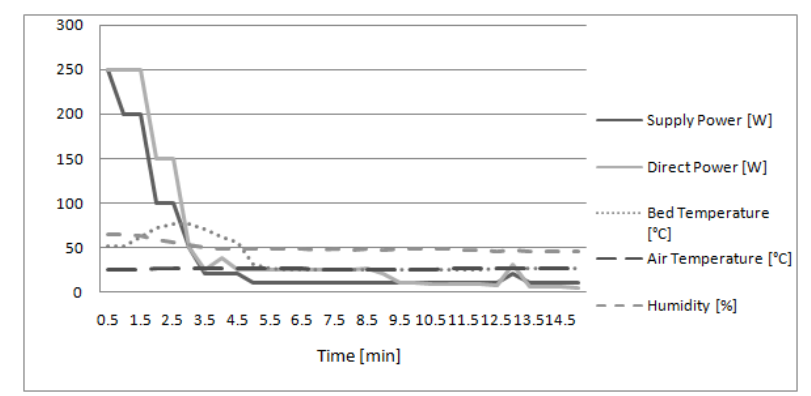

Fig. 3. The Parameter Values using a Variable Microwave Power and Cold Air Jet $(2.5 \div 1.0 \div 0.10 \mathrm{~W} / \mathrm{g}, \mathrm{U}=11.51 \%, \mathrm{G}=75 \%)$. 


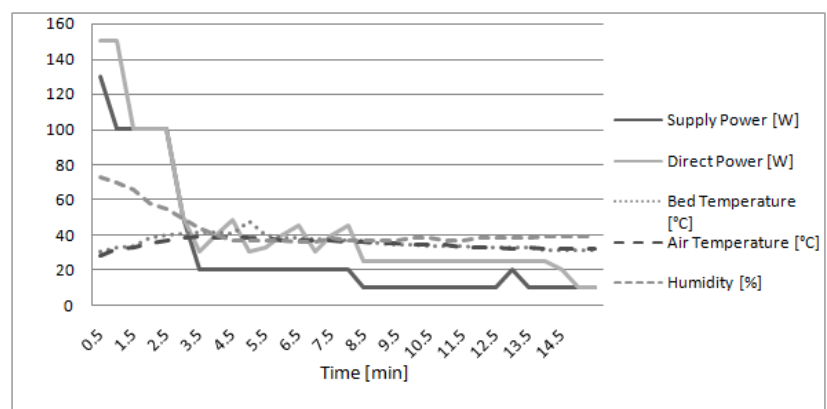

Fig. 4. The Parameter Values using a Variable Microwave Power and Cold/Hot Air Jet $(1.3 \div 0.2 \div 0.1 \mathrm{~W} / \mathrm{g}, \mathrm{U}=12.62 \%, \mathrm{G}=80 \%)$.

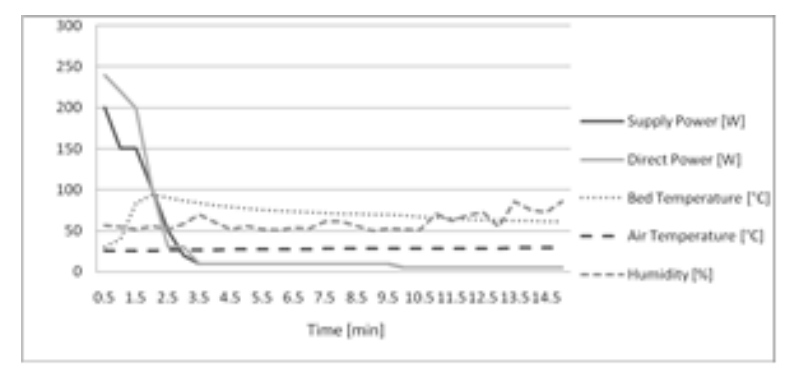

Fig. 5. The Parameter Values using a Variable Microwave Power without Air Jet $(2.5 \div 0.1 \div 0.05 \mathrm{~W} / \mathrm{g}, \mathrm{U}=5.96 \%, \mathrm{G}=25 \%)$.

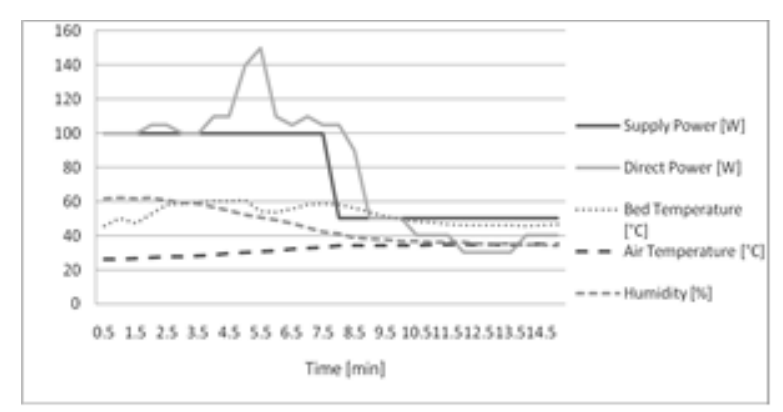

Fig. 6. The Parameter Values using a Constant Microwave Power without Air Jet $(0.2 \mathrm{~W} / \mathrm{g}, \mathrm{U}=2.47 \%, \mathrm{G}=70 \%)$.

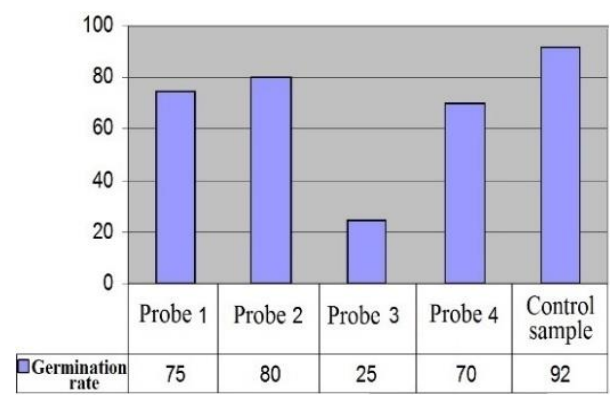

Fig. 7. Corn Seeds Germination after 14 Days.

\section{CONCLUSIONS}

The experimental results presented the process of drying corn seeds using a variable and constant mode microwave power generation. High levels of power should be used as long as the drying speed is high enough. Then power should be applied by lower values for the remainder of drying. By changing the power, density value of $0.75 \mathrm{~W} / \mathrm{g}-0.50 \mathrm{~W} / \mathrm{g}$ to $0.25 \mathrm{~W} / \mathrm{g}$ increases drying time and thus yields a higher energy required to operate in an alternating mode. This study focused on fundamental aspects of research on the microwave drying of maize seed. Based on the results of studies were reached the following conclusions:

1) The applicator has been used successfully to couple microwave energy to the seed bed, the following parameters were monitored during drying: the microwave power, the temperature in the seed bed, the temperature and humidity of the air leaving the outlet of the laboratory installation.

2) On drying of corn seeds for a microwave power density generated by $2.5 \mathrm{~W} / \mathrm{g}-0.1 \mathrm{~W} / \mathrm{g}$ was obtained a more than $92 \%$ germination.

3) Drying time can be substantially reduced by using high values of microwave power absorbed by seeds, but there are detrimental effects on the product quality. Because large temperature and humidity variations adversely affect quality of seeds treated in a microwave field, it is important to continue monitoring the generated power to avoid high temperatures in the seed bed.

Analyzing the obtained results, both by numerical modeling and especially by experimental measurements we can say that the use of the microwave field for drying the corn seeds is useful for reduction of drying time and increasing the quality of the seeds as long as that the maximum permissible values of the drying temperature are not exceeded.

\section{ACKNOWLEDGMENT}

This work was co-financed from the European Regional Development Fund through Sectoral Operational Program "Increase of the Economic Competitiveness" - POS - CCE 2007 - 2013, project number POS - CCE 1843 / 48800, "Increasing the capacity of research - development of the interdisciplinary laboratories for the technologies in electrical engineering", developed by University of Oradea.

\section{REFERENCES}

[1] E.T. Thostenson and T.W. Chou, "Microwave processing: fundamentals and applications", Compos. Pt. A-Appl. Sci. Manuf., 30, pp. 1055-1071, 1999.

[2] T. Leuca, A. Palade, I. Hănțilă, L. Bandici, "The use of hybrid finite element - boundary element method for all the analysis of the operating parameters of a radio-frequency dryin instalation", Revue roumaine des sciences techniques, Série Électrotechnique et Énergétique, 56, 4, pp. 367-376, 2011.

[3] Hassini, L., Peczalski, R., \& Gelet, J.-L., "Combined Convective and Microwave Drying of Agglomerated Sand: Internal Transfer Modeling with the Gas Pressure Effect", Drying Technology,31,8,p.898-904, 2013.

[4] S.O. Nelson, "RF and microwave dielectric properties of shelled, yellow-dent field corn", Trans. ASAE, 22, 6, pp. 1451-1457, 1979.

[5] Wojdyło, A., Figiel, A., Lech, K., Nowicka, P., \& Oszmiański, J., "Effect of Convective and Vacuum-Microwave Drying on the Bioactive Compounds, Color, and Antioxidant Capacity of Sour Cherries", Food and Bioprocess Technology, 7, 3, pp. 829-841, 2014.

[6] F.I. Hathazi, V.D. Soproni, M.N. Arion, C.O. Molnar, "About the use of the high frequency electromagnetic field in order to improve the quality of the agricultural seeds", International Symposium on Fundamentals of Electrical Engineering, Bucharest, pp. 1-4, 2014.

[7] A.R. von Hippel, "Dielectric Properties and Waves", John Wiley Ed., New York, 1954.

[8] Chandrasekaran, S., Ramanathan, S., \& Basak, T., "Microwave material processing-a review", AIChE Journal, 58, 2, pp. 330-363, 2012. 
[9] M.S. Venkatesh, G.S.V. Raghavan, "An overview of microwave processing and dielectric properties of agri-food materials", Biosystems Engineering, 88, 1, pp.1-18, 2004.

[10] T. Ohlsson, N. Bengtsson, "Microwave technology and foods", Advances in Food and Nutrition Research, 34, pp. 65-140 (2001).

[11] Cusacani Guerrero, Julio Agapito, Roman-Gonzalez Avid, “Antennas of Circular Waveguides", (IJACSA) International Journal of Advanced Computer Science and Applications, 10, 8, 2019.

[12] S. Coman, T. Leuca, O. Coman, "Optimization of the dielectric position inside the microwave applicator", Revue Roumaine des Sciences
Techniques Serie Electrotechnique et Energetique. 58,4.pp.357-366, 2013.

[13] Hemis, M., Choudhary, R., \& Watson, D. G., "A coupled mathematical model for simultaneous microwave and convective drying of wheat seeds", Biosystems Engineering, 112, 3, pp. 202-209, 2012.

[14] Holtz, E., Ahrné, L., Rittenauer, M., \& Rasmuson, A, "Influence of dielectric and sorption properties on drying behaviour and energy efficiency during microwave convective drying of selected food and non-food inorganic materials", Journal of Food Engineering, 97, 2, pp. $144-153,2010$ 